\title{
The Anaesthetic Management of a Patient with Maple Syrup Urine Disease
}

\author{
Mahmut Alp Karahan ${ }^{1}$, Hüseyin Sert ${ }^{2}$, İnanç Havlioğlu², Hasan Hüsnü Yüce ${ }^{2}$ \\ ${ }^{1}$ Clinic of Anaesthesiology and Reanimation, Ministry Health Suruç State Hospital, Şanluurfa, Turkey \\ ${ }^{2}$ Department of Anaesthesiology and Reanimation, Harran University Faculty of Medicine, Şanlurfa, Turkey
}

Maple syrup urine disease (MSUD) is an autosomal recessive metabolic disorder caused by a deficit of oxidative decarboxylation of branched-chain aminoacids. It leads to a build-up of leucine, isoleucine, valine, and toxic metabolites in blood and urine, progressing to acute and chronic brain dysfunction. The first symptoms appear in early childhood and are characterized by sweet-smelling urine, with an odor similar to that of maple syrup. At birth, infants seem healthy, but if untreated, they may suffer from neurological deterioration, seizures, hypertonia, or ataxia. During stressful situations, such as infection or surgery, patients may experience severe ketoacidosis, rapid neurological deterioration, and hypoglycemia. We report the anaesthetic management in a child patient with MSUD, admitted for peritonal dialysis catheter insertion with general anaesthesia.

Key Words: Maple syrup urine disease, general anaesthesia, complications

\section{Introduction}

$\mathrm{M}$ aple syrup urine disease is a disorder characterised by the accumulation of leucine, isoleucine, valine and toxic metabolites in the blood and urine as a result of defects in the branched-chain alpha ketoacid dehydrogenase enzyme, which has a role in leucine, isoleucine and valine decarboxylation. The incidence rate of maple syrup urine disease, which is an autosomal recessive inherited metabolic disorder, is 1:120,000 live births. This disease, presenting with an odour similar that of maple syrup, is one of the common metabolic diseases in Turkey. If patients who seem healthy during birth are not treated, neurological pictures, such as ataxia, hypertonia and seizures associated with acute and chronic brain dysfunction, can develop (1). Any stress factor, like infections or surgical interventions, can lead to severe conditions, including ketoacidosis, hypoglycaemia, hyperammonemia, rapid neurological disruption, cerebral oedema and death, in this group (2). In our case report, anaesthesia management was discussed for a 3-month-old patient who was diagnosed with maple syrup urine disease and who would undergo peritoneal dialysis.

\section{Case Presentation}

In the last biochemical examination of a patient who was born as the first live baby from the fourth pregnancy of a 35-yearold mother, with a weight of $2450 \mathrm{~g}$, and who was diagnosed with maple syrup urine disease as a result of examinations carried out due to hypoglycaemia attacks that she had at the age of just 14 days, the ammonia concentration was found to be $144,15 \mu \mathrm{g} \mathrm{dL}^{-1}\left(19-102 \mu \mathrm{g} \mathrm{dL}{ }^{-1}\right)$, lactate concentration was $27.2 \mathrm{mg} \mathrm{dL}^{-1}$, leucocyte value was (WBC) $27.39 \times 10^{3} \mathrm{~mL}$, haemoglobin $(\mathrm{Hb})$ value was $22.21 \mathrm{~g} \mathrm{dL}^{-1}, \mathrm{Ca}^{+2}$ was $0.99 \mathrm{mmol} \mathrm{L}^{-1}$ and glucose level was $77 \mathrm{mg} \mathrm{dL}^{-1}$. It was decided that a peritoneal dialysis catheter would be installed under emergency conditions by a paediatric surgeon for the patient, whose ammonia level had not decreased during the follow-up performed by the paediatric clinic. The 2 -month baby girl was $3 \mathrm{~kg}$ and $49 \mathrm{~cm}$, and she was found to be below the $3^{\text {rd }}$ percentile according to age and gender. In the sampling of preoperative blood gas, mild metabolic acidosis was observed, independent of respiratory compensation (Table 1). After obtaining written informed consent from the parents, the patient's electrocardiography, non-invasive blood pressure, peripheral oxygen saturation $\left(\mathrm{SpO}_{2}\right)$ and body temperature were monitored on the operating table. Infusion of $10 \%$ dextrose, diluted with $0.9 \% \mathrm{NaCl}$ at a proportion of $1: 3$, was initiated as maintenance fluid. The patient was induced with $8 \%$ sevoflurane and successfully intubated with a 3.0 tube without a cuff. Remifentanil was administered at a dose of $0.5 \mu \mathrm{g} \mathrm{kg}^{-1}$, and mainte- 
Table 1. Arterial blood gas values of the patient

\begin{tabular}{|lccc|}
\hline & Preoperative & Intraoperative & Postoperative \\
\hline $\mathrm{pH}$ & 7.33 & 7.363 & 7.37 \\
\hline $\mathrm{PCO}_{2} \mathrm{mmHg}$ & 34 & 38 & 42.5 \\
\hline $\mathrm{PO}_{2} \mathrm{mmHg}$ & 90 & 99 & 95 \\
\hline $\mathrm{HCO}_{3}\left(\mathrm{mmol} \mathrm{L}^{-1}\right)$ & 17 & 20 & 22.5 \\
\hline $\mathrm{BE}\left(\mathrm{mmol} \mathrm{L}^{-1}\right)$ & 8 & 4 & 1.8 \\
\hline $\mathrm{SaO}_{2}(\%)$ & 95 & 97 & 96 \\
\hline $\mathrm{PCO}_{2}$ : partial carbon dioxide pressure $\mathrm{PO}_{2}$ : partial oxygen pressure \\
$\mathrm{HCO}_{3}$ : bicarbonate $\mathrm{BE}$ : base excess $\mathrm{SaO}_{2}$ : arterial oxygen saturation \\
\hline
\end{tabular}

nance of anaesthesia was provided with 3\% sevoflurane and $\mathrm{N}_{2} \mathrm{O} / \mathrm{O}_{2}(50 \% / 50 \%)$. During surgery, blood glucose and blood gas sampling was carried out. The vital signs observed were as follows: systolic blood pressure 74-87 $\mathrm{mm} \mathrm{Hg}$, diastolic blood pressure $37-48 \mathrm{~mm} \mathrm{Hg}$, pulse $110-135$ beat $\mathrm{min}^{-1}, \mathrm{SpO}_{2} 96-99 \%$, body temperature $36.3^{\circ} \mathrm{C}$ and $37.2^{\circ} \mathrm{C}$ and end-tidal carbon dioxide pressure $35-40 \mathrm{~mm} \mathrm{Hg}$. The operation lasted for about 45 minutes, and the patient was taken to the recovery room after being extubated without any problem. As in the preoperative sampling, mild metabolic acidosis, independent of respiratory compensation, was observed in the intraoperative and postoperative blood gas sampling (Table 1). The fluid regimen that was initiated preoperatively and maintained intraoperatively was continued. The patient was followed up for 15 minutes. Her haemodynamic findings were normal, blood glucose was regulated and no complication developed. Then, she was transferred to the patient service.

\section{Discussion}

Evaluating the perioperative physical, biochemical and clinical condition of patients diagnosed with maple syrup urine disease is important for the anaesthetic approach.

The disease can be grouped into classic and variant forms. The classic form is associated with the absence of enzyme activity, and therefore, it includes the most severe biochemical and clinical picture. In the variant forms, the clinical and biochemical picture also varies in parallel with varying levels of enzyme (3). Patients having the classic form are normal during the first week of birth. However, in the following days, ketoacidosis, malnutrition, vomiting, lethargy, hypo- or areflexia and hypertonicity and laxity periods within the first week of life can be observed. The reason for the occurrence of these symptoms at the end of the first week is that it can last for about a week the leucine and 2-oxoisocaproate to exceed the critical concentrations of blood and tissue levels. If this increase is not identified and treated in a short time, the patients can die within a few days or weeks. Permanent brain damage and early death can be prevented with early diagnosis and treatment (4). In our case, hypoglycaemia attacks and symptoms developed on the 14th postnatal day, and the diagnosis of maple syrup urine disease was established with meta- bolic acidosis. In the evaluation of symptoms, it was detected that the disease was consistent with the classic type.

The treatment of maple syrup urine disease is two-stage, and it consists of therapy of acute seizure attacks and long-term nutrition therapy. The aim of the treatment in the acute period is to remove branched-chain amino acids and their metabolites from tissues and body fluids. Peritoneal dialysis is the most effective treatment method and should be performed immediately. Nutrition therapy should be lifelong in patients with maple syrup urine disease. If nutrition therapy is initiated early, the level of brain damage can be reduced to a minimum. Particularly, plasma leucine concentration should be kept at the lowest level, and the essential amino acid leucine should be given in the diet (5).

The anaesthetic approach to patients with maple syrup urine disease should be realised with the choice of a special technique, but the identification of the surgical and anaesthetic effects on metabolism is much more important. Amino acids are released from muscle proteins as a result of insignificant diseases, such as vomiting, diarrhoea and fever and other stressful events leading to a catabolic state. The leucine concentration increases with the accumulation of branchedchain metabolites. Furthermore, malnutrition with infection can accelerate this condition. Accelerated catabolism causes branched-chain amino acids to reach a neurotoxic level, and a rapid hypoglycaemia attack can be seen with contractions. It is important to obtain normal leucine concentrations. In the presence of malnutrition and poor hydration, this concentration can reach high levels, which can increase morbidity (6).

In patients with maple syrup urine disease, the correction of existing acidosis and dehydration by using intravenous fluids preoperatively is significant. However, it should be kept in mind that the fluid regimen that is used can lead to severe hydration, increased intracranial pressure and cerebral oedema (1). Riviello et al. (7) reported cerebral oedema-induced mortality of four paediatric patients with maple syrup urine disease. The use of hypertonic glucose solutions leads to increases in oxygen consumption, $\mathrm{CO}_{2}$ production and noradrenalin excretion and constitutes an additional stress factor for the patient. Therefore, fat emulsions can be preferred for glucose loading without causing hydration and haemodilution. On the other hand, hypoglycaemia episodes can occur in these patients. It is presumed that an excessively high leucine concentration plays a role in this low level of blood glucose. Although it has been revealed that a high leucine level affects the transport of glucose in the intestines or increases insulin levels, its mechanism is not clear. Follow-up of glucose in these patients is an important issue (8).

There are no data showing that any anaesthetic agent is contraindicated in patients with maple syrup urine disease. However, it is important to choose the drug or method in accordance with the surgery that will be performed or complications. The drugs that can cause convulsions should be 
avoided in patients having neurological complications. In the cases presented by Kahraman et al. (1), ketamine was preferred for the first patient, who was to undergo a short orthopaedic operation, because of the absence of neurological complications. The second patient, who had planned to undergo dental surgery, was administered general anaesthesia with propofol due to the presence of neurological complications. Garcia et al. (6) provided induction to a 6-year-old patient with a supracondylar fracture by using ketamine and mivacurium, and they assured maintenance by remifentanil and sevoflurane (6).

In maple syrup urine disease, the technique of anaesthesia should be individualised according to the type of operation and complications associated with the disease. The applications that will cause elevated intracranial pressure should be avoided, since most patients have convulsions and cerebral oedema. Anorexia and vomiting can rapidly progress to lethargy, ataxia and seizure. Patients displaying susceptibility to hypoglycaemia are hypovolemic due to poor nutrition. These patients should be given sufficient fluid therapy and followed up for blood glucose. The preoperative nutrition regimen should be followed carefully, postoperative nutrition should not be delayed and precautions should be taken to prevent vomiting.

Informed Consent: Written informed consent was obtained from patients' parents who participated in this case.

Peer-review: Externally peer-reviewed.

Author Contributions: Concept - M.A.K.; Design - M.A.K., H.H.Y.; Supervision - H.H.Y., M.A.K.; Funding - M.A.K., H.S.; Materials M.A.K.; Data Collection and/or Processing - M.A.K., İ.H.; Analysis and/or Interpretation - M.A.K., H.H.Y., İ.H., H.S.; Literature Review - M.A.K., H.H.Y., İ.H.; Writer - M.A.K., H.H.Y., H.S.; Critical Review - M.A.K., H.H.Y., İ.H., H.S.; Other - H.H.Y., H.S., İ.H.

Conflict of Interest: No conflict of interest was declared by the authors.

Financial Disclosure: The authors declared that this study has received no financial support.

\section{References}

1. Kahraman S, Ercan M, Akkuş O, Erçelen O, Erdem K, Coşkun T. Anaesthetic management in maple syrup urine disease. Anaesthesia 1996; 51: 575-8. [CrossRef]

2. Chuang DT, Shih VE. Maple syrup urine disease (branched-chain ketoaciduria). In: Scriver CR, Beaudet AL, Sly WS, Valle D, Vogelstein B, Childs B, editors. The Metabolic and Molecular Basis of Inherited Disease. New York: McGraw-Hill; 2001: 1971-2006.

3. Langenbeck U. Pathobiochemical and pathophysiological analysis of the MSUD phenotype. In: Abıdı SA, Fekl W, Langenbeck U, Schauder P. Eds. Branched-chain amino and keto acids in healt and disease. Basel: karger, 1984: 315-34.

4. Kaplan P, Mazur A, Field M, Berlin JA, Berry GT, Heidenreich $\mathrm{R}$, et al. Intellectual outcome in children with maple syrup urine disease. J Pediatr 1991; 119: 46-50. [CrossRef]

5. Dixon M, Barnes J. Disorders of aminoacid metabolism, organic acidemias and urea cycle defects. In: Shaw V, Lawson M (eds). Clinical Paediatric Dietetics, Blackwell Scientific Pub, Oxford 1994: 177.

6. Fuentes-Garcia D, Falcon-Arana L. Perioperative management of a patient with maple syrup urine disease. Br J Anaesth 2009; 102: 144-5. [CrossRef]

7. Riviello JJ, Rezvani I, DiGeorge AM, Foley CM. Cerebral edema causing death in children with maple syrup urine disease. J Pediatr 1991; 119: 42-5. [CrossRef]

8. Delaney A, Gal TJ. Hazards of anesthesia and operation in maplesyrup-urine disease. Anesthesiology 1976; 44: 83-6. [CrossRef] 